\title{
Co-Creativity through Play and Game Design Thinking
}

\author{
Sylvester Arnab, Samantha Clarke and Luca Morini \\ Disruptive Media Learning Lab, Coventry University, UK \\ s.arnab@coventry.ac.uk \\ s.clarke@coventry.ac.uk \\ luca.morini@coventry.ac.uk \\ DOI: 10.34190/JEL.17.3.002
}

\begin{abstract}
This article discusses the application of game design thinking as a learning process for scaffolding co-creativity in Higher Education based on the GameChangers initiative (gamify.org.uk) part-funded by the Higher Education Funding Council of England (HEFCE). Taking into account the relationship between play, technology and learning, the game design thinking approach fully embraces and accommodates for the creation and development of games of any typology (board games, card games, digital games, etc.) and playful solutions (gamified products) as freely chosen by the learners, aligning with the importance of autonomy, relatedness and purpose in motivating learners to be deeply engaged in the process. Through this process, learners are expected to gain valuable knowledge in creative and collaborative problem solving and experience game design and development process towards addressing real challenges and opportunities in their communities. The focus of the process is on the creative process rather than the end products/solutions produced by the learners. The paper will specifically discuss the methodology and findings from an experimental module developed based on the approach involving four cohorts of Level two undergraduate students ( $n=122,2017-2019)$. The students came from the different schools and faculties at Coventry University, UK. Based on the qualitative feedback and reflections collected through the Module Evaluation Questionnaire (MEQ) and the final reflection pieces, the co-creative process inspired by play and games demonstrates that through the process, students discover the importance of elements such as empathy, purpose, meaning, art, creativity and teamwork in their learning regardless of the specific disciplines they are pursuing.
\end{abstract}

Keywords: co-creativity, playful learning, game-based learning, game design, higher education

\section{Introduction}

Games, digital or analogue, are increasingly applied for educational, training, and research purposes. Since the mid-1980s, various applied games have been developed, and the application of digital games to support pedagogical goals often seeks to capitalise on growing trends amongst a wide range of target audiences to engage with digital media recreationally. There is also a huge potential for a gameful design to drive social participation and action in the community. The use of game thinking in this sense is expanding the potential for game-based approaches for impacting the society through its very design to engage individuals in serious topics and challenges in their community.

Games are an increasingly culturally relevant form of aesthetic and artistic expression, where they are creative systems that enable play and exploration. Engaging in the creation of a playful system can literate citizenship to not only achieve a higher understanding of complex dynamics across science and society, but to envision, design and act upon creative alternatives. As game designer and scholar Zimmerman (2008) suggests, "being able to successfully understand, navigate, modify, and design systems will become more and more inextricably linked with how we learn, work, play, and live as engaged world citizens." (pp. 25)

Creativity, problem solving, critical thinking and team working have been highlighted as skills for employment expected in 2020 (World Economic Forum, 2016). Designing and creating gameful systems, as an activity on the edge of the diverse fields of Art, Design, Science, Computation and Engineering can be a fertile ground to cultivate such competencies through multi-disciplinary collaboration, providing a playful (engaging), creative and innovative space for people to meet and learn how to fruitfully cooperate.

Inspired by the opportunities for innovative practices enabled by playful co-creativity, this paper specifically focuses on the GameChangers programme (http://gamify.org.uk) that is promoting the application of game design thinking (Arnab, et al. 2017) as an instrument for encouraging learners to understand, apply, test and reflect knowledge in higher education. Findings and insights from an experimental module developed under the GameChangers programme involving three cohorts of Level two undergraduate students $(n=90)$ from the different schools and faculties at Coventry University, UK are discussed. Section 2 will briefly touch on related background in co-creativity and game design thinking, followed by a description of the GameChangers 
approach and the research methodology in Section 3. Section 4 will discuss the findings from the experimental module developed under the GameChangers programme and the article is concluded in section 5.

\section{Background}

While the formal context of a classroom is considered to be a primary location of learning, a majority of student learning activity takes place outside the classroom, where social interaction is a growing part of learning. With this perspective, pedagogy is also shifting, emphasising on active, creative and collaborative learning. Relying more on hands-on activities, classrooms are starting to mirror "real-world work and social environments that foster organic interactions and cross-disciplinary problem-solving" (NMC Horizon Report, 2018 page 4).

To support the shift in pedagogy, there is value in exploiting a design process as a non-linear, iterative and incremental process, which is generative and creative, allowing us to take a complex problem, understand what the problem is and develop possible solutions. Design thinking (Plattner, 2011) as an approach has crossed over to learning, where it is a "way of finding human needs and creating new solutions using the tools and mindsets of design practitioners" (Kelley \& Kelley, 2013, pp. 24-25).

Design thinking is a way to structure an iterative design process, and demonstrates how it is possible to frame a problem so that it is understandable and easy to confront. It uses the idea of creating a product, with an explicit process of brainstorming, finding out the needs of the audience, design, development, testing, sharing, and more. Such a creative and hands-on process can help students and educators break out of the typical classroom model and showcase what learners can achieve. It is a place for students to use different problemsolving styles, to add their own flair to assignments, and to think about the impact they could have on the world.

Capitalising on core motivational drivers, such as autonomy, relatedness, purpose and competence (Ryan \& Deci, 2017), the holistic approach of solving problems by using the design thinking approach could motivating learners to engage with the creative and co-creative process through self-discovery (Reiss, 2002). Learners will be able to discover different solutions in a creative way, which can open up new opportunities for them to engage with meaningful learning experiences that can translate into more sustainable practices in the real world. Purpose can be seen as our need for there to be meaning to our actions. Autonomy refers to selforganising and regulation of one's own behaviour, which includes "the tendency toward inner coherence and integration among regulatory demands and goals" (Deci \& Ryan, 2000; p. 252). Relatedness refers to "feeling connected to others, to caring for and being cared for by those others, to having a sense of belongingness both with other individuals and with one's community" (Deci \& Ryan, 2004; p. 7). Competence in this case refers to seeking the pleasure of being effective in what they engage themselves into. The need for competence would lead individuals to "seek challenges that are optimal for their capacities and to persistently attempt to maintain and enhance those skills and capacities through activity" (Deci \& Ryan, 2004; p. 7).

Education and industry have only very recently started tapping into such huge wells of creativity and cooperation expressed by the diverse manifestations of informal learning spaces which are built around cooperation and design thinking. A key factor in this shift toward a more democratic appropriation of design and computation is the potential for cooperative, community based learning of FabLabs, Hackerspaces and Makerspaces, which, as highlighted by the European Commission report "Growing A Digital Social Innovation Ecosystem for Europe" (EU Comission, 2015a), can become hotbeds of innovation. The report goes on suggesting how cities and governments could further increase the potential for digital and social innovation by investing in some of the spaces and developer communities from where innovation often emerges, such as makerspaces, FabLabs and hackerspaces.

There are also a massive number and growing cultural relevance of the "Game Jam Movement" (see among others; studies carried out by Fowler et al. (2013) about the opportunities game jams offer for rethinking teaching and learning and Locke et al. (2015) for the Movement's disruptive impact on industry practices), being only one of the examples, where almost seven thousand games developed in 48 hours during the 2016 edition of the Global Game Jam, or the 15 Jams organised by the JamToday network to promote healthier lifestyles. 
Games (digital, analogue or hybrid), given their inherently systems-based nature, constitute a powerful path toward actively experiencing systems science and thinking, and creating games or creating solutions inspired by game elements constitutes an invaluable opportunity to get acquainted in a proactive way with the fundamentals of this paradigm (among others: feedback, causal loops, synergy, homeostasis emergence). Game design and making is emphasised as pathway to STEM learning by existing initiatives, such as the Annual National STEM Video Game Challenge in NYC (http://stemchallenge.org) aiming at combining creativity and STEM Skills through video game design. Chiarello and Castellano (2017) also exploit the process of game design for promoting STEM education.

Games Design has also been emphasised as an extremely useful context for developing digital creativity (Nesta, 2013), where designing systems and understanding human behaviour that draws on concepts fundamental to computing (Wing, 2006; Mozelius \& Olsson, 2017). Games present worlds with defined rules, clear objectives and often more than one possible solution to a problem, which enhances the context of both design and computational thinking. Designing, developing and playing games deepen content knowledge, strengthen collaborative skills, combine arts and technology, and build appreciation for the talents of others. The critical thinking skills developed through the process of game design become internalized (Lippl, 2015), game design and computational process supports the thinking skills based on Bloom's taxonomy.

"Innovative new ideas and creative solutions often emerge at the interface between disciplines and involve different societal actors... Linking the arts and humanities with science, technology, engineering and mathematics brings the scientist, engineer, entrepreneur, artist and designer into dialogue to offer the widest range of opportunity and academic and societal insight for experimentation and innovation..." (EU commission, 2015b, p. 20). Successful learning in the 21st century, depends both on networked, horizontal connectedness across a plurality of areas of knowledge and on the communities, which embody this knowledge, be it on a local or a global level.

Moreover, there is a huge potential for a co-creative process through play and games design to drive social innovation in the community. Existing initiatives, such as the Playable City (https://www.playablecity.com/) engages the community towards repurposing existing infrastructures in the city and designing playful activities that addresses urban challenges. Uncharted Power (https://www.u-pwr.co/), a social enterprise is founded based on the Uncharted Play initiative that explored and exploited play and games for developing energy solutions. Games can be "considered a productive method for fostering civic learning, both within formal and informal situations" (Gordon \& Schirra, 2013).

Through the process of game design and design thinking, we can link the arts and humanities with science, technology, engineering and mathematics, which will bring the scientist, engineer, entrepreneur, artist and designer into dialogue to offer the widest range of opportunity and academic and societal insight for experimentation and innovation. This opens up opportunity for such a a process to be adopted and adapted in education that will enhance and enrich the creative and collaborative learning agenda.

\section{Methods and materials}

Inspired by the game design and design thinking approaches as a means for scaffolding multi-disciplinarity, creativity and collaboration, the research has been designed based on the GameChangers programme (Arnab et al., 2017). The programme is an experiential learning programme grounded in constructionist pedagogy (see Ackermann, 2004) that facilitates new models of teaching and learning, and new practice in cross-context learning (in/formal) through the use of game design thinking for creative problem solving - highlighting the importance of activity based approaches and hybrid spaces. Figure 1 illustrates the design thinking process as adapted by the GameChangers programme with a focus on game design.

The programme's key stages and missions (M) are:

- $\quad$ M1 Set the stage and unpack (What do we care about?) - understanding the problems or topics to be addressed during the programme. (Onboarding and Discovery stage)

- $\quad$ 22 Ideation and innovation sketches (What can we do?) - designing possible solutions to a problem at hand, or ways to creatively express a community's particular interests. (Discovery stage) 
- $\quad$ M3 Enabling technologies and solution selection (How can we do it?) - exploring options in enabling tools and technologies, test the tools and consolidate ideas in an iterative way to select the best solution to develop in the programme. (Enthuse stage)

- M4 Mock-ups and Prototyping (How can we make it work?) - developing ideas into working products and mock-ups. (Enthuse stage)

- M5 Testing and reflection (Where do we go now?)- testing the prototypes, iterating on the design and reflecting on the learning process and the potential of the outcomes for further development. (Mastery Stage)

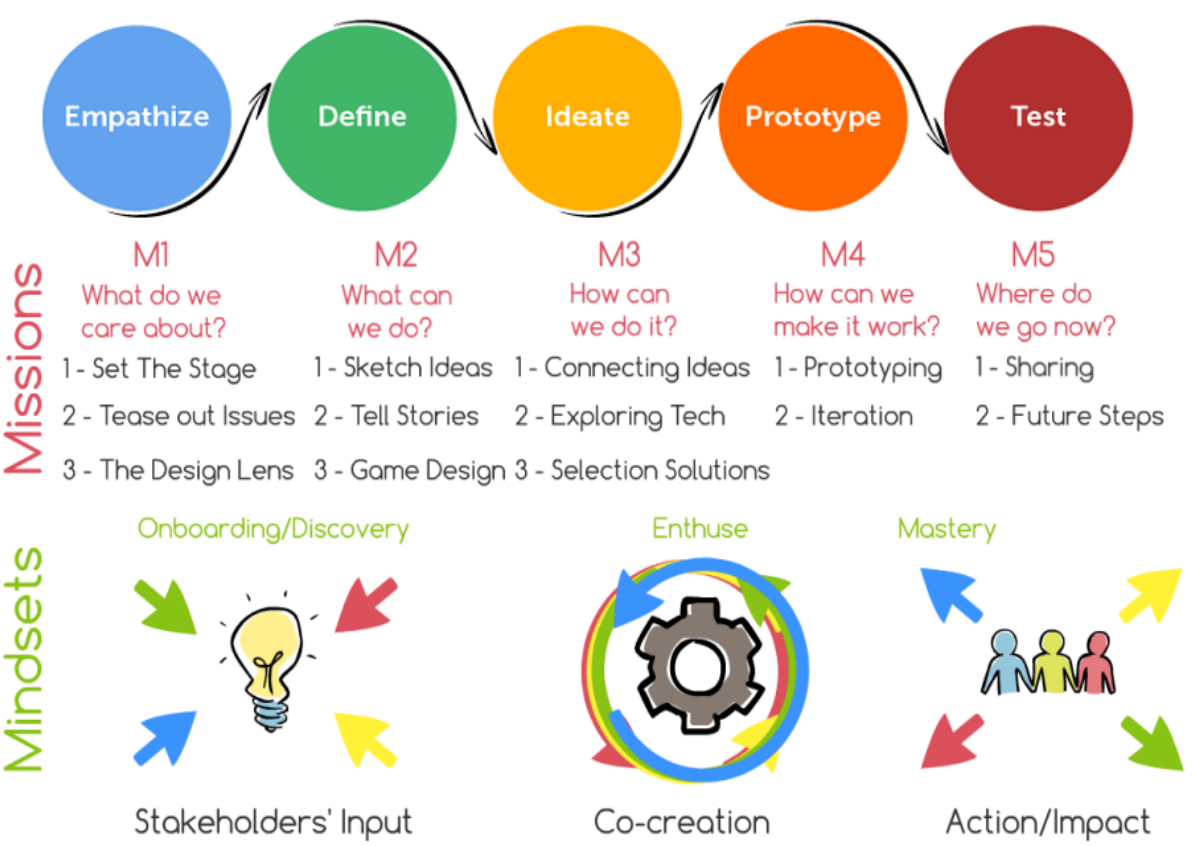

Figure 1: GameChangers' Game Design Thinking approach

A formal undergraduate module on game design thinking (Level 2, 100 study hours, 10 CATS points) has been developed as a research instrument, part of the GameChangers programme and supported by the Higher Education Funding Council for England (HEFCE). This module, which is formally called Playful Design Thinking guides students to apply a playful approach to design thinking inspired by a game design process, which involves solving real world problems with practical, fun and engaging solutions - for example, building a reward/feedback-based game into the act of recycling to encourage sustainable behaviours, redesigning football that could harness energy from rotation, using posters to collect responses on humorous quizzes across the city to encourage the general public to place their chewing gums on the poster instead of throwing them on the floor, etc.

Students reflect on and apply playful design thinking mind-sets, skills and processes to problem-solving and creative thinking for the 21st Century workplace. At the end of the module, students come up with their own playful solutions (e.g. digital or non-digital game-based products) to the selected problems/opportunities and reflect on the design process. Students complete a presentation and submit the reflection on their experiences of the playful design process and the solution they have designed. The design thinking process as illustrated in figure 1 was spread across the 10 weeks, with a focus on M4 and M5 from week 8 to week 10.

One hundred and Twenty Two ( $n=122)$ participants at Undergraduate level 2, have been involved in the Playful Design Thinking module that has so far run over the course of four academic terms consisting of four cohorts (with roughly 30 students each to a cohort - Cohorts $1 \mathrm{~A}, 1 \mathrm{~B}, 2 \mathrm{~A}$ and $2 \mathrm{~B}$ ). These modules ran between September 2017 to April 2019 and took place for 2 hours every Tuesday evening for a maximum of 10 weeks.

Being an elective module offered as an open option to students attending all University's faculties and schools, participants were found to be from different disciplinary backgrounds, such as Engineering, Computing, Arts and Humanities, Business and Law, and the Health and Life Sciences. In each cohort, there was a good mix of different disciplines. Participants were tasked to work in teams and produce a digital and/or non-digital 
application which were to be playful and/or gameful in nature and to respond to the challenges that they identify as a group (see Figures 2, 3 and 5).

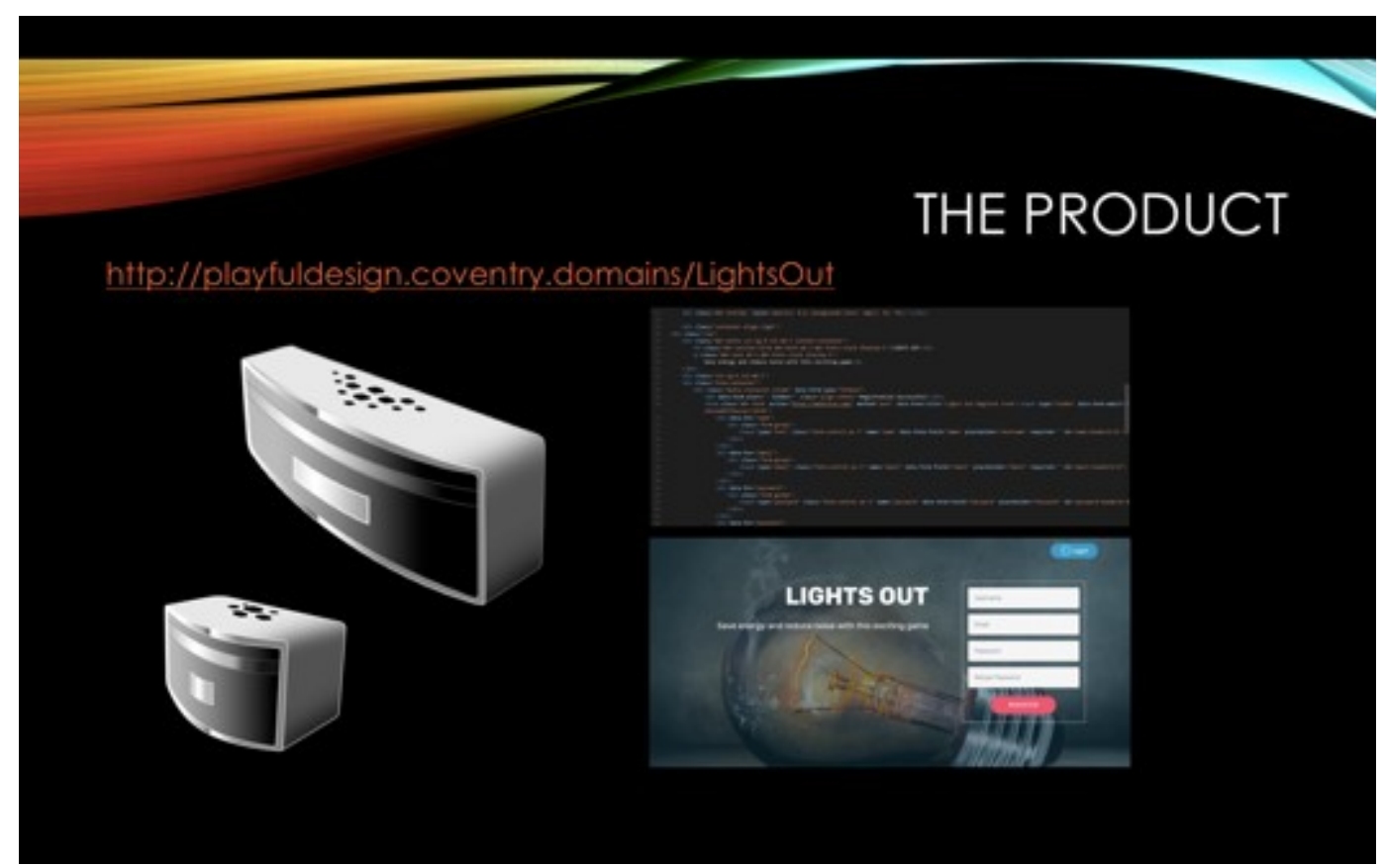

Figure 2: Lights out - a gamified product for managing noise pollution

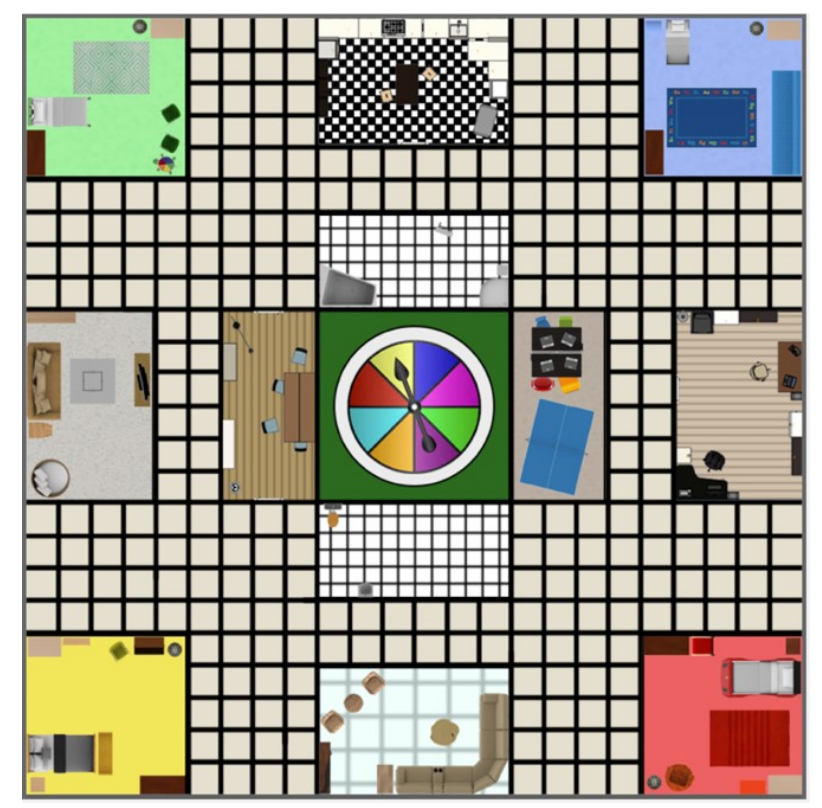

Figure 3: Shutoff Showdown- Board game concept for teaching children about energy consumption around the house 


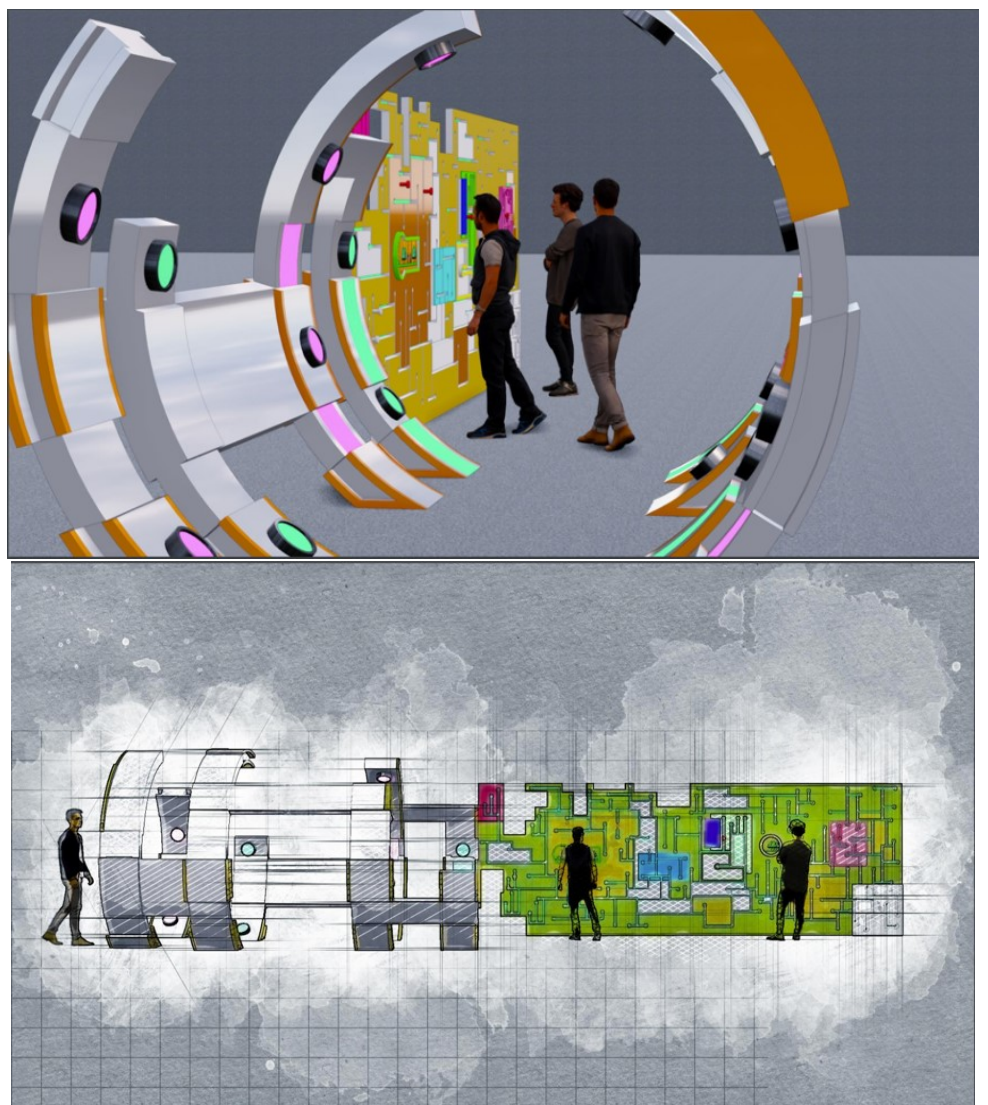

Figure 4: Tappo Concept - To increase activity levels at University for Staff and Students
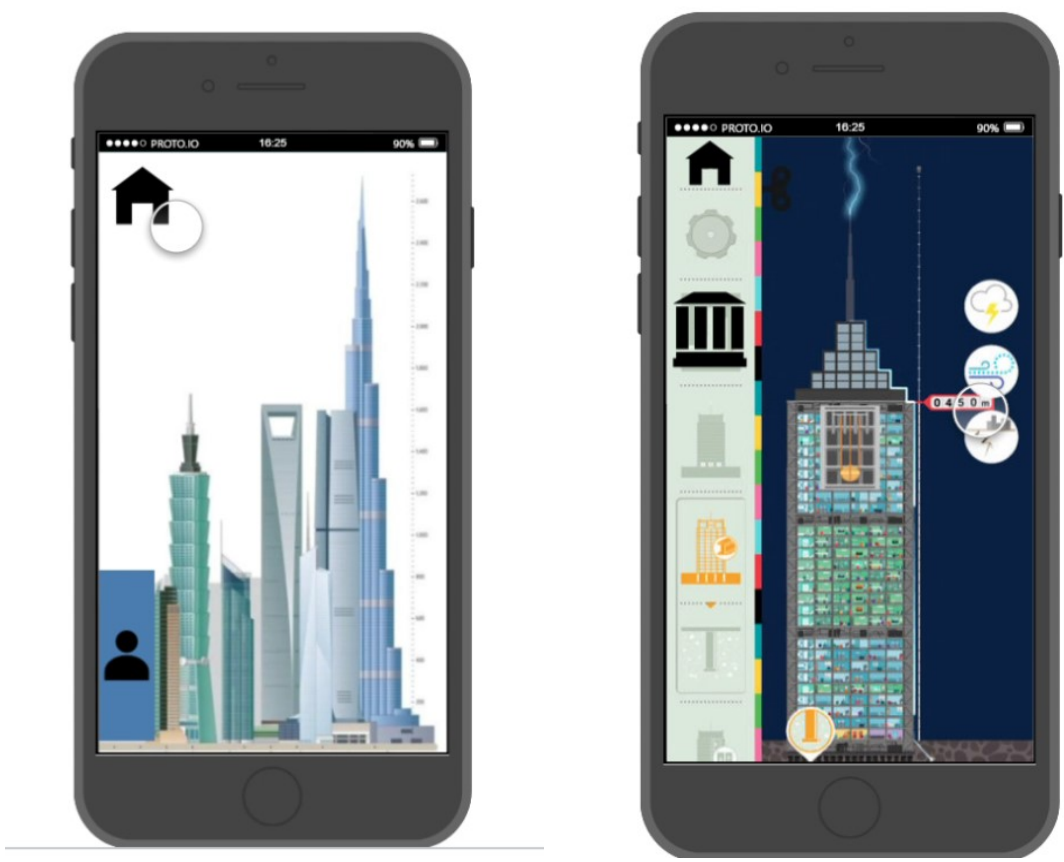

Figure 5: Heights - Concept to encourage Staff and Students at University to walk up and down the stairs.

The interdisciplinary aspect of the module is particularly relevant, in that it made it both harder and much more interesting for people to generate ideas and prototypes across disciplines. An emphasis on co-creation in the course, that is on the necessity of working together across sectors and with intended users, was therefore at the core of the activities, of the theoretical contents and of the ethos. Students were encouraged to come together in groups to select a relevant issue (e.g. sustainability, health, inclusion), ideate a basic solution, 
prototype it and actively engage with prospective users outside of the classroom to iterate a final, co-designed product.

Qualitative data from the official Module Evaluation Questionnaires (MEQ) and Week 10 reflective piece (written submission) were collected. The MEQ for the first cohort was collected in Week 5. Based on the findings of the first cohort, the module decided to collect the MEQ in week 10 at the same time as the reflective pieces. The MEQ for the later cohorts matched the reflective pieces; therefore, the findings from the first cohort will be considered to be signification as part of the discussions in this article. Aside from this structured data gathering, module tutors were, throughout the module, attentive to the climate and discussions in the classroom, complementing the aforementioned questionnaires with qualitative observations. This second layer of data gathering and discussion enabled us to contextualise the outcomes of the questionnaires, and explore their implications and the emerging theme informally but with greater depth. The qualitative feedback was analysed and categorised into themes and they are discussed in the following sections.

\section{Discussions}

\subsection{From confusion to 'light bulb' moments}

When the module was first run, we discovered that divergent thinking related to innovative practices was observed to be a huge challenge for the participants who were not familiar with the concept of game design thinking as an approach. Based on classroom observations and discussions, and on the MEQ feedback taken in Week 5 of the first cohort term, the majority of the students found that the module was 'interesting' and 'innovative' however, assessment was a key barrier for their understanding. Students particularly displayed concerns on how assessment would be conducted.

"At the start of this module, I was very confused as to what we will be doing, unsure about what the end goal is..." - Cohort $1 A-$ Student $A$

"I don't know what I have done for this module" - Cohort 1A Student B

"Clearer advice about how it is marked...". - Cohort 1A Student C

It was clear from the feedback that further refinement and guidance was needed, particularly to support those students who were not from traditional design and arts-based disciplines, around what was expected from them for the modules assessment criteria.

Another issue that was observed in this first cohort was that some students focussed mainly on developing the end product rather than engaging in the learning process itself. It was clear that they were not able to quickly or easily grasp the "outside-of-the-box" nature of the process, and this proved challenging for a large number of the cohort. However, as a whole, the students in the first cohort (1A) recognised that the module was different from what they were used to and appreciated the "relaxed atmosphere" with some students even feeding back that they enjoyed the challenging aspect of the course.

"it's different, interesting to see how work and play go hand in hand," - Cohort 1 A Student D

"mentally stimulating and helps see games from a different angle..." - Cohort 1A Student E

To address and dispel student confusion and misunderstanding over assessment and the learning materials, the module was refined to coincide with the new term and Cohort 1B. This included a strip-back of some of the learning content to match expectations and align more effectively with a 10-credit module taken at Undergraduate level 2. This was found to be successful with the return of cohort 1B's (as well as the later cohort's) MEQ feedback, in which we saw a shift from confusion about the course to students requesting more supporting materials in an online capacity.

\subsection{Serious fun}

Whilst play is often seen as a non-serious endeavour and without greater purpose in higher education, the module actively sought to challenge this assumption by engaging students in playful activities to push 
boundaries in how they conceptualised fun and play in the world. Through the playful design thinking process, the students discovered that fun can have serious and positive consequences and were challenged to innovate on how we deal with real world problems through a playful approach. The students acknowledged through their feedback that getting inspirations from playful activities helped the learning to be more engaging and contextualised.

\section{"I have learnt that learning can be fun! Who would have thought?" - Cohort 1A Student E}

An interesting element that was found from the feedback, was that students felt that this module was where they had experienced 'fun' through learning, but indicated that this was either for the first time or that it was rare for them to feel this way. This has led to deeper questioning about why they had not experienced 'fun' at other points in their learning at University and if so, then why not? Following on from this, another student recognised that;

"it was more memorable when I was learning through playing". - Cohort 1B Student A

The student connects the idea that memory of ideas can come from play, and that play has been a key element to help retention of new knowledge. This allows us to summarise that the importance of play is not just theorised on as a part of the process of design thinking as a concept, but is utilised as a practical element of the learning about design thinking itself. The module was designed to be experimental in its approach, putting play at the forefront of the approach and delivery of the module which has been shown through student feedback across the four cohorts to have been a popular engagement tactic.

"It's creative and a good change from my modules. Something to look forward to." - Cohort $2 B$ Student D

\subsection{Empathy}

One of the most frequently commented on aspects of the module across all four cohorts was the use of 'Empathy' in the design process. Using play and games as inspirations for achieving social innovation was fundamental in allowing students to engage with real challenges/topics and the needs of their target audience.

This was reflected upon and designed into the modules core learning activities. Students were first exposed to existing examples of how social innovation can change behaviour/ impact knowledge \& awareness in a more intrinsic way, so that they could identify how play and games could be used at the heart of the design process.

The students were shown through play and games on how we can exploit this to foster intrinsic motivation in intended stakeholders for developing positive and intended outcomes. The process allowed them to discover the value of "empathy" in everything that they do.

Students reported that understanding about the use of 'empathy' in the design process was a new skill that they gained directly from the module and was a skill that they could use and apply elsewhere.

"the empathy at the core of it will be another useful skill to have in not only the line of work I want to achieve, but in everyday life and social situations..." - Cohort 2B Student B

$$
\text { “... appreciation of different mind-sets and skillsets..." - Cohort } 2 B \text { Student C }
$$

Some students also linked and identified these skills as ones that had not been practised or gained from their main course work.

"...being imaginative and empathetic would greatly help what I am missing from my course...". Cohort 1 A Student $C$

As the study did not track the individual background disciplines that the students came from in regards to feedback, it is difficult to say from which area this was felt to be missed. Although one student indicated that being from a 'computer science' background, meant that 'usability' was not usually considered a priority. 
"What I've learned from studying this module is that when thinking about gamifying a problem such our case (concerning stairs), we need to be able to emphasise with our core audience and see from their perspective. As someone who is a computer science student, we, approach things very technically and we don't see usability as a priority." - Cohort 2A Student C

"doing engineering causes one to become more reliant on maths than creativity. Because of this, designing new learning experiences, where the focus is being imaginative and empathetic would greatly help the hole I am missing from my course." - Cohort 2B Student B

Future work will look to track this information to provide a better understanding on any discrepancies between the disciplines on perceived skills gained in relation to 'empathy' and 'usability'.

Further student feedback In relation to empathy, indicated that the students seemed to really engage with the process of speaking to, and receiving feedback from end users and stakeholder groups as part of their design and development process.

"The feedback from people was incredibly helpful as it aids our progress to be greater. We treat our classmates and lecturers as our client, therefore, we "listen" to their feedbacks and took it into consideration. We basically solved the puzzles with the help of many others thus without them, we would probably be struggling still." - Cohort 2B Student $A$

"I learned that empathy is very important for us as designers and particularly for design thinkers because it allows us to uncover and truly understand the latent needs and emotions of the people we are designing for. This allows us to really emotionally understand just why and how the product needs to be for others to engage with it, not just to target the issue." Cohort $2 B$ Student $F$

"Through researching into the curriculum, I contacted a teacher within Coventry, we found that although the curriculum does begin to cover the topics of energy consumption and the effects on the environment, it is not as effective as it could be, as the children learning about the topic find it interesting but learn about it best when its taught in an age appropriate way." - Cohort $2 B$ Student B

Students also linked this process back to understanding that initial pre-conceived ideas and thoughts about an issue without end-user input, can be limiting as a creator.

"I learnt if you don't have a target market you have nothing to focus on, apart from what you want as the creator." Cohort $2 B$ Student $D$

"This enabled me to find more meaningful solutions as caring and understanding primarily about a different user allows you to create ideas directly aiding others issues." - Cohort 2B Student C

"Empathizing before defining the issue I found opens your mind to more potential outcomes as you have already had relative insight on your problem and a greater desire to fix the issue now because of it. Defining the problem now enables you target more specific aspects within the issue." - Cohort $2 B$ Student $C$

Whilst this step of the playful design thinking process was fed back upon as a positive experience for the majority of students, one indicated that they found it difficult to identify with the 'user needs'.

"I personally found it hard to bond with user needs, as I'm also very sporty I couldn't empathize from a lazy point of view making this one of the more difficult stages for me, it has awoken perspective thinking, putting my feet in someone else's shoes as it were." - Cohort 2A Student B

Ensuring that students are supported through this step is key to helping guide them through the understanding of its importance to the design process. In the module, a range of playful techniques were employed, including that of Lego Serious Play (LSP), so that students could practice opening up and sharing in front of each other. Further work following this feedback will look to grow this area, so that students are given 
the correct support to feel confident in approaching, and working with stakeholder user groups in the 'empathy' stage of their design process.

\subsection{Purpose and meaning}

Students recognised in their feedback that the element of 'fun' alongside empathising with the target audience can play an important role in creating meaningful outcomes. Through the creation of playful activities, the students recognised opportunities to carefully develop experiences that stakeholders could engage with. Most importantly what has come through the feedback across the four cohorts, is that the students recognise that they need to consider purpose and meaning in their creations and designs moving forward for their future careers and endeavours.

"...I have learnt a lot about creating something with purpose beyond initial function, developing an experience rather than a product" - Cohort 1B Student $F$

"I wanted to see my creation spread my message... reach other people through an engaging platform, and hopefully leave a mark inside them" - Cohort 2A Student $E$

"...games can be adapted so others could learn, be more ethical, or change a real-world issue to be solved..." - Cohort $1 A$ Student $B$

"knowing you can create something to help others is very rewarding". - Cohort 2B Student C

It is this realisation from the students that we believe the module has provided a successful example of how teaching playful design thinking can lead to a deeper understanding of meaningful design taught at University Undergraduate level.

\subsection{The Creative Process and Games as an Art Form}

Throughout the module, students are actively taken through the creative process of formulating new ideas and concepts, and are actively encouraged to play around and push boundaries of what they know and believe. Creativity is a top desirable skill in prospective employees, and is a relative skill that can be applied to any discipline. Some students' reflections indicated that they saw the benefit of experimenting with creativity as a way to develop new ideas, but also that they saw how their ideas connected to multiple pathways in the learning process. This understanding was another core area that the module wanted to foster, in helping students to understand that multi-disciplinary thinking and working, would equip them well for future roles in the workplace.

"...a creative mind-set can be just as valuable in a project as lines of code..." - Cohort 1B Student A

"Overall creating and developing the game application was very resourceful and pushed my creative thinking. I've learned to be able to have ideas only stay as ideas if you can't develop them the intertwine with one another, as that solidifies the materiality of the idea."-Cohort $2 B$ Student $E$

"Imagination and creativity were very important in this stage as I found you needed to be able to think of multiple ideas with vast possibilities to achieve the best desired outcome." - Cohort $2 B$ Student $C$

Through the playful design thinking process, students are allowed to discover that the value of understanding and applying a creative process, is also connected to the understanding that not all ideas are right the first time around. It is in the mistakes and iteration process in which they are allowed to learn from unsuccessful design considerations. The idea of 'failure' was reframed and used as part of the learning process, in which students were encouraged that if an idea wasn't suitable then it didn't mean they failed, it just meant they needed to try another way of thinking about their design choices. This was used as a positive experience, with less emphasis on the negative connotations of 'failure'.

"the whole process taught me that it takes many wrong ideas to create a right one" - Cohort $1 \mathrm{~A}$ Student $F$ 
Since games are generally seen by the public as a product designed for pure entertainment reasons, one obstacle can be trying to convince others as to the value that games and play can offer for serious purposes.

Games are also growing as a culturally relevant form of aesthetic, creative and artistic expression, particularly on modern global and political issues. Surprisingly, this was an area that some students identified in their feedback and linked games and play to art from their experience of the module.

"I see games and these playful creations as a form of interactive art, which by its nature is a form of self-expression" - Cohort 1 A Student C

"to sum up, this module has taught me that games can be used just like art to represent feelings, experiences and problems"- Cohort 1B Student F

The feedback suggests that a portion of the students gained necessary skills, to actively link the idea of the creative process to understanding complex and multi-disciplinary paths. These skills as identified previously, are needed for the changing landscape that students face when they leave the University for work. Fostering this creative process, in which students recognise the importance of imagination and process of connecting ideas up effectively, will be part of the continuing work on developing this module. The authors feel that this will be a key area for future consideration of University responsibility and support for our student body.

\subsection{Team work}

One area of the module that was reported across the four cohorts as one of the most challenging elements for the students, was that of working as part of a team. As described before, each student cohort was formed from across the different faculties and disciplines of the University, meaning that they mostly did not know each other in class. Differing course timetables and schedules provided most of the issues for the teams working together, as student team members found it difficult to arrange to meet outside of the modules lesson at a suitable time for all involved. Due to the practical nature of the course work on the playful design thinking module however, it was essential that they did find time outside of the lesson to work on their project together. Despite challenges around meeting and communication between the modules lessons, by week 10, students across the four cohorts displayed closer relationships and had produced a series of interesting and creative gameful and playful concepts for their project work. This was regardless of the short time that they spent together formally each week.

The theme of 'team work' was a popular area for student reflection. Mostly positive reports were received as the students reflected on the benefits and values of working in a team. They also linked 'team working' back to the multi-disciplinary nature of the tasks that were set in the module and how this has helped to understand that different people bring different skills to a project.

"overall, the experience honed my teamwork and marketing skills, appreciation of different mind-sets and skillsets." - Cohort 1B Student D

"the whole process has improved my teamwork skills, marketing skills and environmental consciousness" - Cohort 2A Student C

“...I got to work with many people outside my course..." - Cohort 2B Student B

"Even in a short period of time, we were able to complete our task successfully and I am honoured to be assigned in a group that's extremely dedicated and passionate in what every member does. I have certainly learned and gained knowledge from my team members during the 5 weeks process and would gladly be teamed up with them again if given a chance anywhere in the future". - Cohort $2 B$ Student $A$

Co-creativity and the process of learning how to compromise when working as part of a team was also highlighted as a skill that the module allowed the students to develop.

"What's also required is the skill to work as a group and combine everyone's thoughts into something that's more than a compromise." - Cohort 2B Student E 
Part of the practical design of the module was that it was built to simulate that of a real working environment. By allowing students to take control of their learning through actively allowing them to plan and manage their own team, students could develop these skills of compromise and negotiation so that they could find a balance of when to put forward their ideas and when to allow others to do the same.

Part of ensuring that the inclusion of 'team working' as a learning strategy would be successful, was to build playful activities into the early weeks of the module that encouraged students to open up and feel 'vulnerable' in front of their cohort, but in a safe and structured way through play. Additionally each week, the module tutors would re-emphasise the underlying mantra of the course in that it was a safe space for ideas and that no ideas were wrong. Students were also encouraged not to be discouraging of their peers but to instead provide constructive criticism and ask questions on how they could build on each other's ideas. Student feedback found that there was a positive effect on the students learning process in terms of confidence to share ideas, as several students reported feeling 'psychologically safe' in sharing their ideas to their teams.

"I felt psychological safety applied to me the most this lesson because working in a big group pushed me to take risks without feeling insecure when voicing my ideas." - Cohort 2A Student D

"The psychological safety of the group was high as all group members passed no judgement, and supported the ideas of one another. If there was controversy within the group, it was approached politely with reasonable discussion, so a compromised solution could be made." - Cohort 2A Student E

"The value of not being afraid/shy to share ideas..."- Cohort 1B Student G

This is an element of the playful design thinking module that the authors feel is vital to ensuring future success, in that students feel comfortable in partaking in, and contributing to lesson discussions and new ideas development. By tapping into the use of games and playful activities as part of the process to break down barriers between participants, students ultimately feel more open and comfortable in sharing their stories and ideas with each other.

One aspect of team working should be mentioned here as a caution however, in that disengaged or frequently absent students can cause a difficult working situation for the others members in their team, as reported below in one students reflections.

"I found these lessons more difficult as we were reduced to 3 people when most of the group were absent, including the project manager. However, I gained personal motivation from this, as it gave me an opportunity to take charge and push the team forward towards the goal. I'm now more comfortable with leading a large group towards a common goal as the previous 3 lessons made me see how taking that risk can benefit myself as well as the team." - Cohort $2 A$ Student $D$

However, in this scenario it is better to encourage the students that are present, that they control the direction of the project whilst others are not available. Tutors also made it clear in these cases, that students would not be penalised for lack of effort shown by team members which went some way to helping dispel fears connected to assessment.

\subsection{Playful Design Thinking as an Approach}

As part of the students' reflective activities, the tutors asked students from across the four cohorts to summarise what they believed they had gained from participating on the playful design thinking module. The feedback that was given across all active students enrolled on the four cohorts, produced a series of responses that all contained positive reflections of their experience and skill gain as a direct result of the module. No negative responses were received in relation to this feedback. Below is a selection of some of the feedback received in response to this task.

"I think it has taught me a new way to discover innovative solutions. Implementing this throughout this module I think it is a very reliable model to generate ideas from a different point of view primarily from empathizing with the users beforehand to gain knowledge into what might not be the best solution but the one that helps the most to reduce empathy towards the issue." - Cohort 2B Student C 
"Overall, through learning to identify and apply the steps of design thinking process, we were able to design and produce a concept of a playful experience or product for our targeting audience. By identifying their needs, we were able to understand how to define the problem and solution. And through many iterations, coming up with new ideas, revising existing ones, improving others, we were able to come up with a solution that reflects our understanding of playful design thinking." Cohort $2 B$ Student $E$

"It has improved my design thinking because prior to this module I would jump straight into ideating instead of researching and defining a problem. I now know that it is better to research before you start because if you don't you might create something that doesn't solve the problem." - Cohort 2A Student A

"Overall what I have gained from this module is that I taught me to be more open minded. It also helped me to listen other people ideas and consider their issues when applying our concept to the game. As well as the fact that this is group project and that all inputs and ideas should take to consideration." - Cohort $2 A$ Student $C$

"I now feel like I have gained an important skill when it comes to solving real world issues and understand the process of developing solutions in a playful way to aid others." - Cohort $2 B$ Student C

Students report a variety of skills gained including the ability to consider end-users, conducting research effectively, defining problems, becoming open-minded, ideas generation and the ability to consider others input and ideas. It is clear from the student feedback that has been gathered to date, that the playful design thinking module has come quite a way in positively addressing and impacting development of core skills with the students. As the module is an ongoing experiment, it is constantly being adapted and refined in order to use the students feedback to improve the core content and delivery. The latest cohort (2B) of the module completed the MEQ questionnaire in February 2019 which put the module at a 97.3 satisfaction score across the student body with a sample of the written feedback as detailed below (Table 1).

Table 1: Module MEQ Feedback Feb 2019

\begin{tabular}{|l|}
\hline Creativity, assessment and the environment of the classes. \\
\hline It's fun, creative and you do something new. \\
\hline Get to work in groups. \\
\hline Creative. \\
\hline A good change from my modules. \\
\hline Something to look forward to. \\
\hline Clear deadlines are set. \\
\hline We know exactly what we have to do. \\
\hline The lectures are interesting. \\
\hline Interactive. \\
\hline Refreshing. \\
\hline Passionate course leader. \\
\hline Subject is interesting. \\
\hline Lecture is helpful and straight to the point. \\
\hline Lecture makes advantage interesting and willing to help out of classes. \\
\hline
\end{tabular}

\section{Conclusions}

The medium of play and games provides a particularly favorable environment to enact pedagogical innovation as, being interactive by definition, it allows participants to directly and explicitly engage with both the iterative (re)design of the formal, computation based rule system that defines the game mechanics and with the learning-from-failure that comes from engaging in interactive scenarios. Games present worlds with defined rules, clear objectives and often more than one possible solution to a problem, which enhances the context of design thinking. Based on the experimental module, we found that designing, developing and playing games through the GameChangers programme has the potential to further deepen content knowledge through the creation and application and testing of solutions, promote empathy in a learning process, allow for the discovery of purpose and meaning as intrinsic motivation, combine arts and technology, strengthen collaborative skills and build appreciation for the talents of others (nurturing cross-disciplinary hard and soft skills). The creativity and co-creativity developed through the process of design thinking with emphasis on 
using play and games as inspirations has the potential to sustain the students' mind-set and practices long term, which will impact how they engage with their studies, the community and the world of works.

Teaching is also a research tool in this case (Ainsley, 2014). The experimental module that has been used as our research instrument has been maintained as one of the formal elective modules beyond Cohort $1 A$. The following iterations (1B, $2 \mathrm{~A}$ and $2 \mathrm{~B}$ ) informed by the findings from Cohort $1 \mathrm{~A}$ has led to the module to provide more scaffolding in the earlier weeks to help students to "acclimatise" to the process faster including ensuring that the assessment was further clarified in the beginning. The outcomes synthesised from all four cohorts in this article demonstrate that this module has really enhanced the students' experience in HE and will have value beyond their formal educational endevours.

As part of the overall GameChangers initiative, the content of the module has also been adapted into an open educational resources (OER), accessible via the programme's website (http://gamify.org.uk) and associated to the various workshop templates and toolkits. The initiative has also now been adapted in Malaysia through the Newton Funded CreativeCulture project (http://mycapsule.my), where teachers and students are developing their own playful educational resources and implementing them in rural schools in Borneo. This demonstrates the value and impact of playful design thinking, which should be included in education for promoting creative and empathetic problem solving.

\section{Acknowledgements}

This work has been supported by the Higher Education Funding Council for England (HEFCE), the Newton Fund (AHRC) and the Disruptive Media Learning Lab.

\section{References}

Ackermann, E. K. (2004), Constructing Knowledge and Transforming the World, In: M. Tokoro and L. Steels (Eds.) A learning zone of one's own: Sharing representations and flow in collaborative learning environments, Amsterdam, Berlin, Oxford, Tokyo, Washington, DC. IOS Press, 2004. pp. 15-37

Ainley, P. (2014). Teaching as Research. In Sparking Ideas: Sharing Educational Innovation.

Arnab, S., Morini, L., Green, K., Masters, A. and Bellamy-Woods, T. (2017), We are the Game Changers: An Open Gaming Literacy Programme, International Journal of Game-Based Learning (IJGBL), Vol. 7 No. 3, pp. 51-62.

Chiarello, F. and Castellano, M. G. (2017), Board Games Creation as Motivating and Learning Tool for STEM, In: Pivec, M. and Gründler, J. (Eds), Proceedings of the the 11th European Conference on Game-Based Learning ECGBL 2017, Academic Conferences Publishing, 2017, p. 448-454

Deci, E. L., \& Ryan, R. M. (2000). The "what" and "why" of goal pursuits: Human needs and the self-determination of behavior. Psychological Inquiry, 11(4), 227-268. Page 252

Deci, E. L., \& Ryan, R. M. (2004). Overview of self-determination theory: An organismic dialectical perspective. In E. L. Deci \& R. M. Ryan (Eds.), Handbook of self-determination research (pp. 3-33). Rochester, NY: University Of Rochester Press

EU Commission (2015a), Growing A Digital Social Innovation Ecosystem for Europe [Online] Available from: https://www.nesta.org.uk/sites/default/files/dsireport.pdf Accessed: [30th April 2018]

EU Commission (2015b), Science Education for Responsible Citizenship [Online] Available from: http://ec.europa.eu/research/swafs/pdf/pub science education/KI-NA-26-893-EN-N.pdf Accessed: $\left[30^{\text {th }}\right.$ April 2018]

Fowler, Al., Khosmood, F., Arya, A. and Lai, G. (2013). The Global Game Jam for Teaching and Learning. Proceedings of the 4th Annual Conference of Computing and Information Technology Research and Education New Zealand (CITRENZ2013), At Hamilton, New Zealand

Gordon, E. and Schirra, S. (2013), Game Based Civic Learning in Public Participation Process, In: De Abreu, B. S. and Mihailidis, P. [Eds], Media Literacy Education in Action: Theoretical and Pedagogical Perspectives, Routledge, pp. 153

Kelley, T. and Kelley, D. (2013), Creative Confidence, New York: Random House, pp. 21-25.

Lippl, C (2015), Games and Blooms Taxonomy [Online] Available from: http://zulama.com/education-trends/gamesblooms-taxonomy/ Accessed: [30 ${ }^{\text {th }}$ April 2018]

Locke, R., Parker, L., Galloway, D., \& Sloan, R. (2015). The Game Jam Movement: Disruption, Performance and Artwork. In Workshop Proceedings of the 10th International Conference on the Foundations of Digital Games (Pacific Grove, California, Asilomar Conference Grounds)

Mozelius, P. and Olsson, M. (2017), Learning to Program by Building Learning Games, In: Pivec, M. and Gründler, J. (Eds), Proceedings of the the 11th European Conference on Game-Based Learning ECGBL 2017 /, Academic Conferences Publishing, 2017, p. 448-454

Nesta (2013), Game design to develop computational thinking [Online] Available from: http://www.nesta.org.uk/blog/game-design-develop-computational-thinking\#sthash.eRJOHVah.dpuf Accessed: [30 ${ }^{\text {th }}$ April 2018]

NMC Horizon report preview (2018), Higher Education Edition, Educause. 
Plattner, H (2011), An Introduction to Design Thinking PROCESS GUIDE [Online] Available from: https://dschool.stanford.edu/groups/designresources/wiki/36873/attachments/74b3d/ModeGuideBOOTCAMP2010 L.pdf Accessed: [30th April 2018]

Reiss, S. (2002). Who Am I? The 16 basic desires that motivate our actions and define our personalities. New York: Berkley Trade Paperback

Ryan, R. \& Deci, E. (2017). Self-determination theory: basic psychological needs in motivation, development, and wellness. New York, NY: The Guilford Press

Wing, J. M. (2006), Computational thinking. Commun. ACM 49, 33-35.

World Economic Forum (2016), The Future of Jobs - Shareable Infographics [Online] Available from: http://reports.weforum.org/future-of-jobs-2016/shareable-infographics Accessed: [30 ${ }^{\text {th }}$ April 2018]

Zimmerman, E. (2008). Gaming literacy: Game design as a model for literacy in the twenty-first century. In Perron, B. \& Wolf, M. (Eds.), The Video Game Theory Reader 2, (pp. 23-31). New York: Routledge 